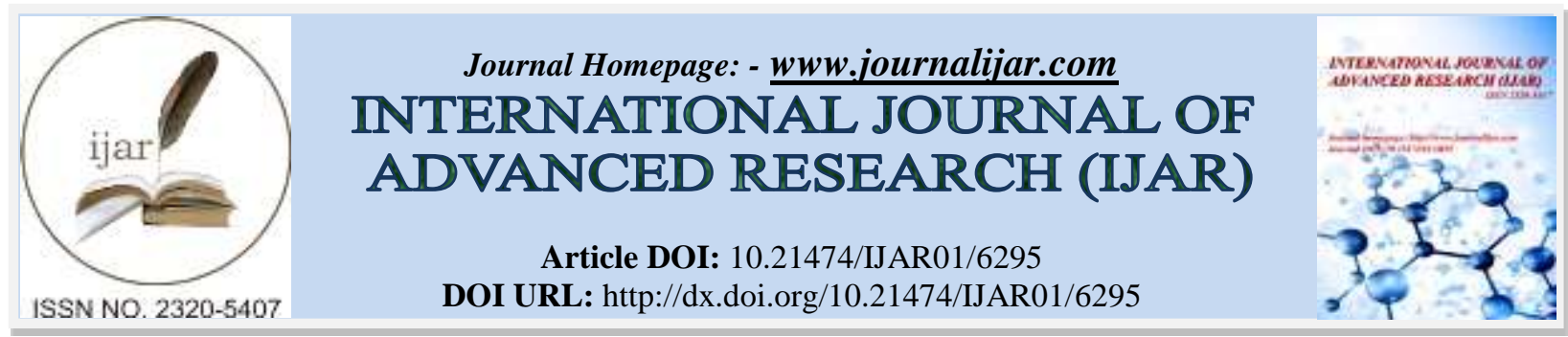

RESEARCH ARTICLE

\title{
CRUMB RUBBER AS ASPHALT MODIFIER.
}

\section{Varun $^{1}$, Aditya Arya ${ }^{1}$ and Satya Prakash ${ }^{2}$.}

1. Transportation Engineering, Dept. of Civil Engineering, IIT Delhi, India.

2. Dept. of Civil Engineering, GEC Raipur, India.

\section{Manuscript Info}

Manuscript History

Received: 12 November 2017

Final Accepted: 14 December 2017

Published: January 2018

Key words:-

Ambient, Crumb Rubber, Crack

Resistance, Fatigue Resistant,

Resilience.

\begin{abstract}
This study presents the properties, performance and findings on crumb rubber as asphalt modifier and accomplishes the comparison between the performances of Crumb Rubber Modified Asphalt over conventional asphalt, the rheological and mechanical performances of various mixtures evaluated by different experimental techniques. In this study it is observed that with increase in percentage of the fine CR in the mix resulted in increase of viscosity and a decrease in resilience of pavement. CR modification at high additive content exhibited higher elastic response than the styrene butadiene styrene (SBS) modified mixture. It is evident from the various researches and studies that CRM asphalt can increase high temperature stability, strengthen low temperature crack resistance, enhance water stability, durability and fatigue resistance of asphalt pavement. The use of crumb rubber in the asphalt binder has great advantages including increase in life of pavement, retarded reflection cracking and thus reducing maintenance cost of the pavement.
\end{abstract}

Copy Right, IJAR, 2018,. All rights reserved.

\section{Introduction:-}

This research paper deals with the production and use of crumb rubber as asphalt modifier in the construction of flexible pavement and the inter alia consist of introduction, literature review, methodology, engineering properties, environmental concerns, availability, conclusion and references. Factors such as high traffic intensity, overloading of trucks, daily and seasonal change in temperature are responsible for rutting, raveling, undulation, cracking, bleeding, water damage and low fatigue resistance. One of the major causes of flexible pavement deterioration is fatigue failure. To avoid these drawbacks and to increase the durability and stability of pavement, the properties of conventional asphalt need to be improved. To improve the property of the conventional asphalt different types of materials have been investigated and available as additives for asphalt modifications such as Plastics (Polyethylene, Ethylene Butyl Acrylate etc), Elastotomers (Styrene Butadiene Styrene, Styrene Butadiene Rubber etc) and Reclaimed Rubber (Tyre Crumb Rubber).

Polymers like SBS and SBR are very expensive and increase the overall construction cost so they are rarely used. However the use of $\mathrm{CR}$ in asphalt modification not only improves pavement performance but also reduces environmental pollution by recycling large number of waste tyre products and also it is economical (Hamed, 2010). When the ordinary asphalt pavement is compared with CRM asphalt pavement, the result shows that CRM asphalt pavement can increase high temperature stability, strengthen low temp crack resistance, enhance water stability and 
improve the performance of durability and fatigue resistance as compare to conventional asphalt pavement. (SHI Hongpo et al.,2005), (HUANG Wen-yuan,2004), (Magdy A. A, 1997), (Heitzman M., 1992).

The use of crumb rubber in the asphalt binder reported great advantages including increase in life of pavement, retarded reflection cracking, reduced maintenance cost (Baker and Connolly, 1995; Baek et al.,2009; Lee et al.,2006; Liang and Lee, 1996; Ruth and Roque, 1995; Shen et al.,2005,2006). Crumb rubber modified (CRM) binder have other unique applications also such as Open-Graded Friction Courses (OGFC), Stress Absorbing Membrane (SAM), Chip Seals (Cooper et al.,2007; Shen et al., 2005).

\section{Literature Review:-}

ZHANG. Wen-wu. performed various tests like dynamic shear rheometer and bending beam rheometer to study the properties of CRM asphalt. Results showed that when asphalt was modified, performances of anti-rutting, anticracking and anti-fatigue are improved and when particle size of rubber powder was increased the temperature sensibility of asphalt decreased whereas temperature stability increases distinctly.

Hak-Seo Kim, Soon-Jae Lee, and Serji Amirkhanian done a study in which CRM asphalt was made using virgin binder of performance grade (PG) 64-22 with various percentage of ambient rubber as 10\%, 15\%, 20\% by weight of virgin binder and found that during the interaction process, crumb rubber particles swell after absorbing a portion of the oils in the binders, resulting in increase of binder viscosity. Different tests were carried out on prepared CRM asphalt and it was found that viscosity of binder increases as rubber concentration increases and also when rubber mixing percentage reaches to $20 \%$ flow characteristics changes from Newtonian flow to shear thinning flow. It was also found that when stress is removed from CRM asphalt minimum deformation in binder was observed which shows that with addition of rubber content elasticity of asphalt improves.

Kök. B. Vural .et. al (2013); studied the performances of bitumen and asphalt mixtures modified by crumb rubber (CR) and compared with those modified by styrene-butadiene-styrene (SBS). Some experimental studies have been done to evaluate the rheological and mechanical performances of resultant mixtures. The result shows that it is necessary to use twice as much CR as SBS to reach the same performance attained by SBS. Also CR modification at high additive content exhibits higher elastic response, i.e., recoverable strain, than the SBS-modified mixture.

Lee .S. Jae. et. Al. (2007) focussed on the improvement of the properties of binder when mixed with crumb rubber modifier. In this study, a laboratory investigation was conducted on the properties of CRM binders as a function of CRM processing method and percentages. A total number of twenty-four CRM binders ( 3 binder sources * 2 CRM processing methods * 4 CRM percentages) were produced and artificially aged through an accelerated aging process. The results indicate that the higher CRM percentages for CRM binders lead to a higher viscosity, a better rutting resistance and a less chance for low temperature cracking. In general, the ambient CRM was found to be more effective on producing the CRM binders that are more viscous and less susceptible to rutting and cracking.

Hussain U. Bahia and Robert Davies also studied the effect of the modifiers on rheological, failure, and aging properties of the asphalts. The results were somewhat different from the others. CRM's resulted in increased viscosity at pumping and mixing temperatures. This effect was not favourable, since it makes pumping of binders, mixing, and compacting of HMA produced with these modified binders found to be more difficult.

\section{Methodology:-}

Production of crumb rubber:-

Every year millions of tyres are discarded and becomes scrap. Out of these $20 \%$ reused and around $15 \%$ are used in different alternative but the disposal of remaining tyres is a major problem and environment issue due to lack of landfill space. Crumb Rubber (CR) is obtained mainly from scrap tyres, at ambient temperature the steel and tyre cord is removed and leaves behind tyre rubber with granular consistency. There are two major methods of producing crumb rubber i.e. ambient grinding and cryogenic grinding. In ambient grinding process the whole tyre is passed through a shredder which breaks it into smaller chips. Then these smaller chips are fed into granulator in which chips are converted into smaller size, the steel in the tyre are removed magnetically and fiber is removed through a combination of shaking screens and wind sifters. After checking the material and by ensuring that it does not contain any steel or fiber it is passed through different machines to form crumb rubber like secondary granulators, high speed rotary mills, extruders or screw presses, cracker mills according to material size needed by customers. 
Whereas in Cryogenic grinding process tyres used are pre-treated in the form of chips or even smaller in size if it is possible. Then the material is allowed to flow in a freezing chamber where liquid nitrogen is used to cool it from 80 to $-120^{\circ} \mathrm{C}$. The temperature below freezing point is used because at this temperature rubber behaves as a flexible material and it can be easily crushed and broken. This frozen rubber is poured into hammer mill in which rubber get break into small pieces and also a small screen is provided into hammer mill which easily separates fiber and metals present in the tyre. The crumb rubber obtained after this process lastly passes through magnetic screens to remove if any impurity left. The following are the basic disadvantages of crumb rubber obtained from cryogenic process:

1. Use of liquid nitrogen which over all increases manufacturing cost

2. Crumb rubber obtained has a smooth surface texture with low surface area which increases reaction time due to which target viscosity of crumb rubber modified asphalt suffers.

Therefore in manufacturing of crumb rubber ambient grinding process is generally used.

\section{Production of Crumb Rubber Modified Asphalt:-}

There are two methods of obtaining modified asphalt by mixing crumb rubber: wet process and dry process. In wet process crumb rubber is mixed with binder and sufficient time is provided for reaction before mixing of aggregate. In this process no chemical reaction takes place between the crumb rubber particles and the binder but there is a diffusion of aromatic components of the binder into the crumb rubber due to which viscosity is reduced (Heitzman 1992). The reduced in viscosity depends upon the type of the rubber, binder and the mixing temperature. At the same time, there is a decrease in the quantity of aromatic oils thereby increasing the viscosity of the mix while the volume of rubber particles increases due to swelling. To compensate for this increased in viscosity due to addition of rubber; extender oils are used and provide sufficient aromatic components for the crumb rubber. By increasing the percentage of extender oil there is a increase in ductility and reduction in resilience.

The second method is dry process in which the crumb rubber, binder and aggregate are mixed together simultaneously. In this process the aggregate particles are replaced by the crumb rubber particles in the asphalt concrete mix. Sufficient time is not provided for significant reaction between crumb rubber and the binder. The dry process application have varying performance which lead it to acceptable and unacceptable ranges this is because of improper control on the volume changes due to the swelling of the crumb rubber during mixing and handling.

According to ASTM D6114, crumb rubber should have following properties to produce modified asphalt

1. Moisture should be less than $0.75 \%$ and should be free flowing

2. Specific gravity should be $1.15 \pm 0.05$

3. It should not contain any visible nonferrous metal particles by weight

4. Ferrous metal particles should not be more than $0.01 \%$ by weight

5. All rubber particles should pass through No. $8(2.36 \mathrm{~mm})$ sieve

6. For hot mix binder application fiber content shall not exceed $0.5 \%$ by weight

\section{Advantages of Crumb Rubber over Conventional Asphalt:-}

1. Lower susceptibility to daily and seasonal temperature variations

2. Higher resistance to deformation at elevated pavement temperatures

3. Better adhesion between aggregate and binder

4. Higher fatigue life

5. Delayed cracking and reflective cracking

6. Overall improved performance in extreme climatic conditions and under heavy traffic conditions

7. Better water resistance

8. Higher resistance to rutting

9. Resistance to creep and higher indirect tensile strength

\section{Properties and Specifications:-}

There are different selection criteria defined for crumb rubber modified bitumen (CRMB), polymer modified bitumen (PMB) and natural rubber modified bitumen (NRMB) based on atmospheric temperature as per (IRC: SP: 53-2002). 
Table 1:- Specification for Crumb Rubber Modified Bitumen (CRMB) as per IRC:SP:53

\begin{tabular}{|c|c|c|}
\hline Designation & CRMB 60 & NRMB 40 \\
\hline Penetration at $25^{\circ} \mathrm{C}, 0.1 \mathrm{~mm}, 100 \mathrm{~g}, 5 \mathrm{sec}$ & $<50$ & $30-50$ \\
\hline Softening point, ${ }^{\circ} \mathrm{C}(\mathrm{R} \& \mathrm{~B})$, minimum & 60 & 60 \\
\hline Elastic recovery of half thread in ductilometer at $15^{\circ} \mathrm{C}$ & 50 & 30 \\
\hline Flash point, $\mathrm{COC}{ }^{\circ} \mathrm{C}, \min$ & 220 & 220 \\
\hline Separation, difference in softening point, $\mathrm{R} \& \mathrm{~B},{ }^{\circ} \mathrm{C}$, maximum & 4 & 4 \\
\hline \multicolumn{3}{|c|}{ Thin Film Oven Test (TFTO) on residue } \\
\hline Penetration at $25^{\circ} \mathrm{C}, 0.1 \mathrm{~mm}, 100 \mathrm{~g}, 5 \mathrm{sec}$, Minimum, $\%$ Of original & 60 & 60 \\
\hline Decrease in softening point, $(\mathrm{R} \& \mathrm{~B}),{ }^{\circ} \mathrm{C}$, Maximum & 5 & 5 \\
\hline Elastic Recovery of half thread in ductilometer at $25^{\circ} \mathrm{C}$, Minimum & 35 & 25 \\
\hline
\end{tabular}

The viscosity and amount of asphalt binder in an HMA mix will affect the compatibility of the mixture, the higher the viscosity of the binder, the stiffer the mix at a given temperature. Asphalt-rubber mixes must be compacted while it is in hot stage. Compaction is generally not a problem if the temperature is maintained. The criticality of the temperature increases as the rubber content increases. It is found that the presence of CRM may generate fumes and smoke at typical compaction temperatures. The compaction can be accomplished with either vibratory or steel-wheel rollers as the rubber-modified binder tends to pick up with Pneumatic wheels.

\section{Conclusion:-}

From the above studies it is found that the use of CRM is economical as compared to commercial polymers like SBS and SBR. The use of crumb rubber in asphalt modification which is obtained by ambient grinding is not only improves the pavement performance but also reduces environmental pollution by recycling large no of waste tyre products. When comparing the ordinary asphalt pavement with CRM asphalt pavement, the result shows that CRM asphalt pavement shows better result than conventional bitumen pavement. The CRM asphalt pavement has high temperature stability, rutting, raveling, undulation, cracking, bleeding, water damage and low fatigue resistance, strengthen low temp crack resistance, enhance water stability and improve the performance of durability. It is observed that with increase in percentage of the fine $\mathrm{CR}$ in the mix resulted in increase of viscosity and a decrease in resilience of pavement. CR modification at high additive content exhibited higher elastic response than the styrene butadiene styrene (SBS) modified mixture. It is evident from the various researches and studies that CRM asphalt can increase high temperature stability, strengthen low temperature crack resistance, enhance water stability, durability and fatigue resistance of asphalt pavement.

\section{References:-}

1. Baha Vural Kok ; Mehmet Yilmaz ; Alaaddin Geckil (May 26, 2013), "Evaluation of Low-Temperature and Elastic Properties of Crumb Rubber-and SBS-Modified Bitumen and Mixtures”, Journal of materials in civil engineering from American Society of Civil Engineers.

2. T. J. Lougheed, and A.T. Papagiannakis, Members ASCE (August 1996), "Viscosity Characteristics of RubberModified Asphalts", Journal of materials in civil engineering from American Society of Civil Engineers.

3. Nuha S. Mashaan , Asim Hassan Ali, Mohamed Rehan Karim and Mahrez Abdelaziz (September 2011), “An Overview of Crumb Rubber Modified Asphalt", Center for transportation research, faculty of engineering, university of Malaya.

4. Zhao-yi HE, Zhao-feng LU , Wen-wu ZHANG (2010), "Performance study on rubber powder modified asphalt of waste tyre", American Society of Civil Engineers

5. Hak-Seo Kim, Soon-Jae Lee and Serji Amirkhanian (February 2010), "Rheology Investigation of Crumb Rubber Modified Asphalt Binders" Korean Society of Civil Engineers

6. Davide Lo Presti (2013) "Recycled tyre rubber modified bitumen for road asphalt mixtures" Nottingham Transportation Engineering Centre, University of Nottingham U.K.

7. Federal Highway Administration, U S department of Transportation

8. Soon-Jae Lee, Chandra K. Akisetty, Serji N. Amirkhanian (2007) "The effect of crumb rubber modifier (CRM) on the performance properties of rubberized binders in HMA pavements" Department of Civil Engineering, Clemson University, Clemson, SC 29634-0911, United States

9. Hussain U. Bahia and Robert Davies "Effect of Crumb Rubber Modifiers (CRM) on

10. Performance-Related Properties of Asphalt Binders" The Pennsylvania State University, University Park PA.

11. IRC:SP:53 - 2010, 2002

12. IRC:107 - 2013 